\title{
Perspectivas y contribuciones para la traducción entre lenguas románicas
}

\author{
Francisco JaVier CAlvo del Olmo ${ }^{1}$ \\ Universidade Federal do Paraná, Brasil \\ francisco.olmo@ufpr.br
}

Recibido: 8 de enero de 2015

Aceptado: 15 de abril de 2015

\section{RESUMEN}

Este artículo delimita un área interdisciplinaria entre la traductología, la filología y lingüística románicas inscrita en los estudios teóricos, restringidos a un grupo lingüístico de acuerdo con Holmes (1972/1988/2000). Con este objetivo, presentamos, en primer lugar, la Romania como espacio pluridimensional, donde se hablan las lenguas neolatinas, para formular una propuesta de traducción intrarrománica. Acto seguido, examinaremos los elementos lingüísticos, literarios, culturales e históricos que jalonan el proceso de traducción entre, para y desde idiomas de dicho grupo. Evaluamos las posibilidades y límites de tal propuesta y concluimos apuntando algunas líneas de investigación que se abren para futuros estudios.

Palabras clave: lenguas románicas, interdisciplinariedad, traducción intrarrománica.

Perspectives and contributions from translation between Romance languages

\begin{abstract}
This paper aims to describe an interdisciplinary area between Translation Studies and Romance linguistics and philology, an interface in the area-restricted theories of the map of Holmes (1972/1988/2000). To this purpose, first we present the Romania as multidimensional space, where different Romance languages are spoken, and we formulate a proposal of Intra-Romance-group translation. Then we analyze linguistic, literary, cultural and historical components that mark the process of translation between, to and from languages of
\end{abstract}

\footnotetext{
1 Este artículo presenta algunos de los resultados de mi tesis de doctorado en traductología (Universidad Federal de Santa Catarina, Florianópolis, Brasil) que contó con financiación de la AECID-MAEC (Agencia Española de Cooperación Internacional y Desarrollo) y de la CAPES (Coordenação de Aperfeiçoamento de Pessoal de Nivel Superior), órgano dependiente del Ministerio de Educación de Brasil. Cf. Calvo del Olmo (2014).
} 
that group. We evaluate the possibilities and limits of such a proposal and, finally, we offer potential research lines open for future studies.

Keywords: Romance languages, interdisciplinary, Intra-Romance-group translation.

Sumario: 1. Introducción. 2. Interdisciplinariedad entre la traductología y la filología románica. 3. La Romania como espacio pluridimensional. 4. Las tradiciones traductológicas en el ámbito latino y románico. 5. Una propuesta da traducción intrarrománica. 6. Conclusiones y perspectivas para futuros estudios.

\section{Introducción}

Tal y como se ha venido desarrollando en las últimas décadas, podemos considerar la traductología como una disciplina autónoma dentro de las ciencias humanas con objetivos, métodos y paradigmas propios. No obstante, el mismo Holmes (1972/1988/2000), al demarcar este incipiente campo del conocimiento, señaló que una disciplina nunca se crea ex novo pues recibe las aportaciones de áreas adyacentes y de modelos precedentes, "older disciplines" en sus propias palabras. Tales modelos y paradigmas preexistentes, al ser aplicados a la nueva disciplina, podrían demostrarse insuficientes para resolver las necesidades de los investigadores; en esos casos, se hace necesario buscar nuevos enfoques o reformular ciertos conceptos. Por esta razón, el mismo autor llama la atención sobre la necesidad de abrir canales para que la traductología no discurra exclusivamente dentro de las vías exploradas por otras áreas.

En el mismo artículo, Holmes estructura la traductología apuntando varias líneas que deberían orientar el trabajo de los investigadores; así, separa estos estudios entre los aplicados y los puros (no aplicados) que, a su vez, se dividen en descriptivos y teóricos, en estos últimos además marca una distinción entre estudios generales y parciales. Asimismo, los estudios puros, teóricos, parciales están compuestos por subclases que varían según el tipo de restricción que presenten; entre ellas se encuentran aquellos trabajos suscritos a determinada área (area-restricted) considerando como tal:

Area-restricted theories can be of two closely related kinds; restricted as to the languages involved or, which is usually not quite the same, and occasionally hardly at all, as to the cultures involved. In both cases, language restriction and culture restriction, the degree of actual limitation can vary. Theories are feasible for translation between, say, French and German (language-pair restricted theories) as opposed to translation within Slavic languages (language-group restricted theories) or from Romance languages to Germanic languages (language-group pair restricted theories). (Holmes 1972/1988/2000: 74)

Así pues, la reflexión que abordaremos en este artículo se encuadra en el mapa de Holmes como un estudio teórico, restringido a un grupo lingüístico (language-group pair restricted theories) ya que presentaremos, discutiremos y evaluaremos algunos 
elementos que aparecen en el proceso de traducción entre lenguas pertenecientes a la familia románica o neolatina que comparte una filiación lingüística y una historia de recíprocos intercambios culturales y literarios. No forma parte de nuestros actuales objetivos examinar las relaciones lingüístico-literarias del grupo románico como otros idiomas, o familias lingüísticas; por ello enunciamos nuestro análisis como una propuesta de traducción intrarrománica. Asimismo, destacamos la pertinencia del adjetivo intrarrománico para delimitar el campo de nuestro estudio; es decir, las relaciones lingüísticas, culturales, históricas y literarias que atraviesan el orbis latinus.

\section{Interdisciplinariedad entre la traductología y la filología románica}

Como explicamos, la traductología adopta un abordaje interdisciplinar, en diálogo con otros campos de estudios humanísticos y sociales. En ese sentido y dentro del área delimitada en el punto anterior, aquellos estudios que traten la traducción entre lenguas románicas encontrarán una sólida base en la filología y la lingüística románica, disciplinas que se ocupan del estudio de las lenguas neolatinas, procedentes del latín vulgar, de la descripción interna de estos idiomas, de su historia externa y de sus manifestaciones literarias. Esta familia lingüística, hoy presente en los cinco continentes, cuenta con una historia de veintisiete siglos, si partimos de la fecha mítica de la fundación de Roma o de los testimonios epigráficos más antiguos conservados. Así, la Romanística demarca un extenso campo de estudios ya que:

Muchos fenómenos culturales fundamentales de la Humanidad han sido ideados en una lengua románica. El antiguo provenzal fue la primera lengua del amor cortés, en que el poeta rinde homenaje a la dama, código de conducta que con todos sus convencionalismos sigue influenciando nuestros comportamientos sociales. Francesco Petrarca (1304-1373) cantó en italiano las diferentes facetas de su amor por Laura, creando con sus sonetos un modelo literario imitado en toda Europa hasta el siglo XVIII. En español se escriben los primeros tratados circunstanciados modernos de historia natural y antropológica sobre países nuevos, como la General y natural historia de las Indias y Tierra firme del mar Océano de Gonzalo Fernández de Oviedo $(1535,1547,1557)$ y la Historia natural y moral de las Indias del Padre José de Acosta $(1590,1591,1608,1614)$. En francés se redacta la primera enciclopedia moderna exitosa, la Encyclopédie, ou dictionnaire raisonné des sciences, des arts et des métiers de Denis Diderot y Jean le Rond d'Alembert (1751-1772) y también en francés se formula la primera declaración de los derechos humanos (Déclaration des droits de l'homme et du Citoyen, 1789). En la época de la formación de los Estados nacionales, los poetas rumanos Vasile Alecsandri (1819-1890) y Mihai Eminescu (1850-1889) enseñan cómo se puede crear una literatura nacional integrando plenamente las tradiciones populares. Y en el siglo XX, el poeta portugués Fernando Pessoa (1888-1935) se disocia en diferentes heterónimos (Alberto Caeiro, Álvaro de Campos, Ricardo Reis), cada uno con una existencia vital propia, poniéndonos en evidencia cómo en todos nosotros existen diferentes personalidades, cada una con su propia cosmovisión y sus propias formas de expresión. Trece autores franceses (Sully Prudhomme 1901, M. Maeterlinck 1911, R. Rolland 1915, A. Gide 1947, F. Mauriac 1952, A. 
Camus 1957, Saint-John Perse 1960, J. Sartre 1964, S. Beckett 1969, C. Simon 1985), diez autores de lengua castellana (J. Echegaray 1904, J. Benavente 1922, G. Mistral 1945, J. R. Jiménez 1956, M. A. Asturias 1967, P. Neruda 1971, V. Aleixandre 1977, G. García Márquez 1982, C. J. Cela 1989, O. Paz 1990), seis de lengua italiana (G. Carducci 1906, G. Deledda 1926, L. Pirandello 1934, S. Quasimodo 1959, E. Montale 1975, D. Fo 1997), un autor portugués (J. Saramago 1998) y un autor de lengua provenzal (F. Mistral 1904) fueron galardonados con el premio Nobel de literatura. (Metzeltin 2004: 16)

De igual manera, las posibilidades de investigación que este grupo de lenguas ofrece, desde diversos enfoques teóricos y con objetivos diferentes, son inmensas; por ese motivo "es raro que un solo estudioso, el 'filólogo románico', domine un campo tan vasto" (Renzi 1982: 17); lo cual hace que sea necesaria una especialización, un foco concreto, para examinar y profundizar en una determinada cuestión.

La filología y la lingüística románica alcanzaron una notable pujanza en el siglo XIX, unida al desarrollo de la lingüística histórica y del método comparativo, que pretendía establecer relaciones entre lenguas y entre literaturas. Sin embargo, a lo largo del siglo XX, la Romanística se fue diluyendo debido, en buena medida, a la inmensidad de sus objetivos y a la cantidad de cuestiones que planteaba. Durante ese período, también fueron cambiando los intereses científicos al recibir contribuciones que exigían "una radical reducción de cuestiones que ya le habían parecido centrales a la investigación precedente, pero que ahora han perdido el lugar que ocupaban, mientras que cuestiones secundarias nos parecen ahora fundamentales" (Renzi 1982: 19). La traducción -desde lenguas neolatinas para lenguas neolatinas o entre lenguas neolatinas- había ocupado una posición secundaria en los estudios románicos; nuestra propuesta, sin embargo, pretende establecer un área común entre la romanística y la traductología, aplicando el conocimiento acumulado por la primera a las investigaciones, problemas y cuestiones que se plantean en la segunda, reformulando o revalidando cada una sus propios paradigmas.

No obstante, delimitar este espacio interdisciplinar entre la traductología y la romanística abre toda una serie de interrogantes: ¿qué cambios implica en la reflexión teórica o en su aplicación empírica ubicar la traducción entre las lenguas románicas en un referencial común?, ¿es efectivo marcar tal especificidad?, ¿qué elementos deben considerarse en el proceso de traducción entre tradiciones próximas o distantes?, además de la filiación al latín compartida por estos idiomas, ¿debemos considerar el peso de la proximidad cultural, histórica y geográfica en que se desarrollaron y actualmente conviven? Si las lenguas románicas pertenecen a una tradición europea y occidental junto a otros idiomas, ¿qué es lo que las aparta de esa tradición?, ¿qué es lo que las une o divide entre sí?, ¿qué elementos las vinculan a otras tradiciones?, ¿en qué medida todas estas cuestiones tienen validez para las comunidades latinohablantes o romanófonas ubicadas en regiones que no forman

\footnotetext{
${ }^{2}$ Tales como los países francófonos y lusófonos de África o la población hispanohablante y lusófona de América Latina.
} 
parte del área ancestral donde se formó la familia lingüística?², ¿cómo se (re)configuran dichas relaciones en los actuales movimientos de diásporas y migraciones, en los procesos de hibridación, en los flujos entre fronteras físicas, virtuales y discursivas? En definitiva, cuáles son las cisiones y los paralelismos, las divergencias y las convergencias, las dinámicas centrípetas o centrífugas que atraviesan esta órbita lingüística y cultural.

En todo caso, no se cierra aquí la nómina de cuestiones; y otros investigadores podrían sumar nuevos interrogantes que sirvan para explorar, cartografiar, clasificar y desglosar este campo interdisciplinar de modo que los diversos trabajos, estudios y proyectos que lo atraviesen no se pierdan en su vastedad.

\section{La Romania como espacio pluridimensional}

Berman $(2007)^{3}$ afirma que las obras literarias mantienen una estrecha relación con las lenguas vernáculas, ya que estas son por esencia más icónicas que la coiné estandarizada. Sin embargo, él mismo defiende que solo las coinés, las lenguas estandarizadas, se pueden traducir y, por tanto, es necesario alcanzar cierto grado de estandarización en la lengua de llegada. Consecuentemente, el desafío para la traducción literaria es articular una trama de vernaculares (dialectalismos, neologismos y registros diferentes) capaz de acoger la lengua extranjera en su especificidad. Así pues, se produce una tensión entre la lengua de partida y de llegada que debe encontrar un equilibrio sobre las coordenadas de lengua estandarizada/coiné/culta y polifonía diatópica/diacrónica/diafásica/diastrática. Con el fin de entender las relaciones recíprocas que las lenguas románicas -y sus locutores- establecen, dedicaremos este epígrafe a hacer una exposición sucinta de las tensiones que se manifiestan en el ámbito lingüístico neolatino enmarcado en los actuales procesos globalización y cambios culturales ${ }^{4}$.

El término Romania le sirvió a la lingüística románica ${ }^{5}$ para denominar "el conjunto de tierras en las que se habla alguna lengua derivada del latín" (Badia i Margarit 2007: 25). Dentro de este vasto espacio, es posible distinguir la Romania Continua; aquellos territorios - conquistados por Roma- en los que se ha hablado latín en los últimos dos mil años sin interrupción. La Romania Continua se localiza en la Europa meridional, "desde el Atlántico y a lo largo del Mediterráneo, con dos puestos de avanzada, uno en el norte de Francia y otro en Rumanía" (Posner 1998: 249). Según esta clasificación existe un continuum lingüístico que desde la Península Itálica cruza los valles alpinos, atraviesa el arco mediterráneo y el Midi francés, penetra en la Península Ibérica por los Pirineos, recorre la meseta castellana y, finalmen-

\footnotetext{
${ }^{3}$ Como se puede consultar en las referencias bibliográficas, he utilizado las traducciones brasileñas de las obras Berman (2002 y 2007) por ser las que tenía a disposición durante la redacción de este artículo.

${ }^{4}$ Remito a otro trabajo anterior para una exposición pormenorizada de la Romania como carrefour linguistique. Cf. Calvo del Olmo (2012).

5 Este término aparece en todos los manuales publicados en las últimas décadas; Tagliavini (1993), Posner (1998), Renzi y Andreose (2009).
} 
te, llega al extremo occidental y al litoral Atlántico como podemos observar en el Mapa 1.

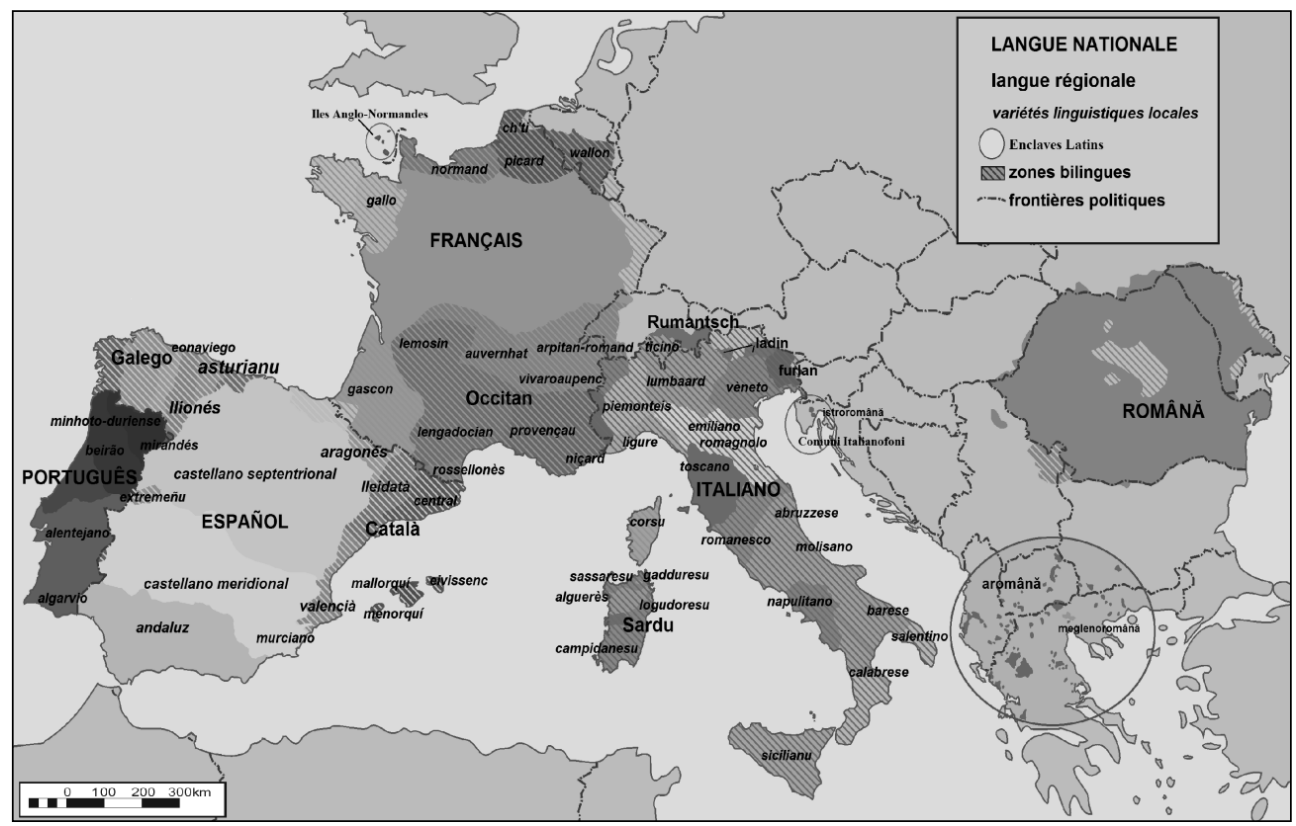

Mapa 1: La Romania Continua a comienzos del s. XXI ${ }^{6}$

Ahora bien, la extensión actual de la Romania Continua no coincide con el limes, las fronteras, del Imperio de Trajano, época de máxima extensión territorial de Roma hacia el 117 d. C. Ello se debe a que "en algunas regiones, el latín desapareció, arrinconado y substituido por nuevas lenguas que se impusieron" (Badia i Margarit 2007: 27). Tal fue el caso del Norte da África, Gran Bretaña o buena parte de los valles alpinos de la actual Suiza y Austria. Todos esos territorios reciben el nombre de Romania Submersa.

Sin embargo, "esas pérdidas fueron compensadas con creces por la difusión de algunas lenguas románicas (como el español, el portugués y el francés) fuera de Europa (sobre todo en América, pero también en África y en Asia)" (Badia i Margarit 2007: 27). Estos vastos espacios, incorporados a la esfera neolatina en los últimos cinco siglos, conforman la Romania Nova, que abarca buena parte de América, más de la mitad del continente africano y algunos enclaves en el sureste asiático como podemos observar en el Mapa 2.

${ }^{6}$ Documento gráfico de elaboración propia. 


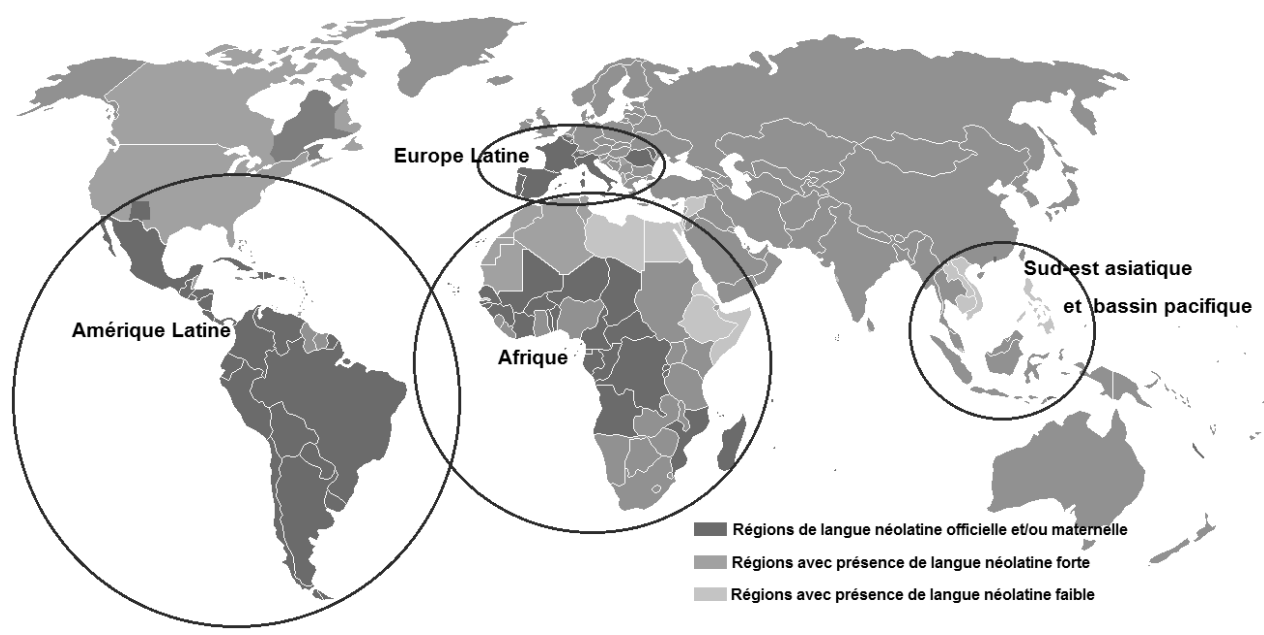

Mapa 2: La Romania Nova a comienzos del s. $\mathrm{XXI}^{7}$

Ahora bien, las relaciones geográficas e históricas no son las únicas que articulan el espacio lingüístico neolatino pues a ellas se suman aspectos culturales, antropológicos, políticos e identitarios. Así, Posner (1998: 67) distingue entre "lenguas "orgánicas", no alcanzadas por la manipulación y remodelación conscientes, y lenguas "inorgánicas", interlectos o koinés, estándar o no estándar". La misma autora señala que en sociedades complejas no existen realmente lenguas orgánicas y, en su lugar, lo que hay son lenguas históricas; partiendo de esta premisa, postula una diferencia:

Aunque los dialectos locales y similares puedan ser considerados también "lenguas históricas", sería útil distinguir el exclusivista "club" románico, formado por las lenguas nacionales y literarias, de la numerosa "familia" románica, con sus prolíficas ramificaciones, que se extienden desde la unidad nuclear, que vive en el sur de Europa, hasta los miembros más lejanos de la familia, fruto de la emigración a los límites de los antiguos imperios. (Posner 1998: 67)

La visión de la autora da continuidad a cierta concepción jerárquica de las lenguas pues, a pesar de que todas procedan del latín, no todas serían igualmente legítimas y apenas aquellas que lograron un alto grado de prestigio cultural y político, fundamentalmente las lenguas nacionales y/o literarias, pueden pertenecer al club. Esa división separaría la Romania Maior, correspondiente al club románico, y la Romania Minor, correspondiente a un amplio grupo de idiomas, dialectos, patois, hablas y argots de límites porosos y difusos, disperso por los cinco continentes con diversos grados de codificación, historicidad y vitalidad. De acuerdo con Milroy

\footnotetext{
${ }^{7}$ Documento gráfico de elaboración propia.
} 
(2011), las lenguas de la Romania Maior concentran los valores políticos, sociales e incluso económicos, dispersos en el mosaico de la Romania Minor ya que la estandarización garantiza una mayor eficiencia en todo tipo de intercambios.

Frente a la dificultad de formular clasificaciones exhaustivas y cerradas, el profesor e investigador brasileño Marcos Bagno propone establecer grupos al interior de la familia neolatina y, así, delimita un grupo portugalego que abarcaría la diversidad del portugués brasileño, el portugués europeo, el portugués africano, el gallego y los varios criollos de base lexical portuguesa. Además de ese grupo, la familia románica contendría otros "el itálico, el romanche, el gálico (francés, wallón, quebequense etc.), el sardo, el corso, el occitánico, el catalánico, el roménico (rumano, moldavo etc.), el asturleonés, el hispánico (castellano, andaluz, ladino, mexicano, cubano, peruano, argentino, paraguayo, etc.)" (Bagno 2011: 203). Esta propuesta abriría una serie de posibilidades para la traducción intralingüística, es decir, la adaptación de una obra escrita en Portugal al público brasileño, la actualización de un texto medieval en la lengua estándar correspondiente o la elaboración de diccionarios entre español y argentino, o entre francés y quebequés, por ejemplo.

Por otro lado, la condición minoritaria ${ }^{8}$ de una lengua "no está relacionada simplemente con aspectos numéricos o cuantitativos, sino fundamentalmente cualitativos" (Lagares 2011: 170). Así, el portugués y el húngaro cuentan, en suelo europeo, con un número de hablantes que ronda los diez millones y un área de distribución geográfica de aproximadamente 93.000 kilómetros cuadrados; sin embargo, la situación de ambos idiomas diverge significativamente ya que el húngaro tiene escasa distribución más allá de sus fronteras nacionales, mientras que el portugués es una lengua internacional, oficial en nueve Estados y en diversos organismos supranacionales, hablada por los cerca de 250 millones de lusófonos que viven en América del Sur, África y Asia. De la misma manera, una lengua puede ser mayoritaria en un lugar y estar en una situación de lengua minorizada en otro: tal es el caso del mismo portugués, en el estado indio de Goa y en otros antiguos enclaves de Asia. O el español, que es la lengua hegemónica en los 21 países que lo tienen como idioma oficial y lengua materna de la mayoría de su población, pero está minorizado en las prácticas de la diáspora hispana residente en los EEUU, donde se encuentra en una situación de diglosia y amenazado por la sustitución lingüística y la aculturación de las nuevas generaciones.

Además de lo dicho, la existencia de una Romania Maior y Minor se puede relacionar, en el actual contexto, con dos dinámicas divergentes que actúan sobre nuestras comunidades: la primera tendente a la globalización, a la homogeneización centrípeta, y la segunda tendente al multiculturalismo centrifugo, a la reivindicación de la diversidad humana. En el momento actual, el inglés ocupa una posición hiper-

${ }^{8}$ Los adjetivos maior y minor son comparativos y, por tanto, establecen una relación semántica de superioridad o de inferioridad entre dos objetos, nociones estrictamente relacionales. Se clasificada una lengua en la categoría de minoritaria o mayoritaria no por ser hablada en un área más o menos amplia o por una población más o menos numerosa, sino al compararla con el número de hablantes o el área que abarca otro idioma con el que dicha lengua puede, inclusive, estar en contacto o/y en conflicto. 
central como idioma que domina la gran mayoría de ámbitos económicos, científicos, culturales, tecnológicos, políticos y de producción material; por lo que todas las demás lenguas están expuestas a la influencia constante de este idioma. Al trasladar esas dinámicas al ámbito lingüístico que aquí estudiamos, Lagares (2013) expone que existen dos ideologías igualmente contrapuestas: la del anonimato y la de la autenticidad. Las lenguas hegemónicas con proyección internacional asumen la ideología del anonimato que no identifica a sus hablantes como individuos o comunidades concretas, sino como un público general y abstracto. La lengua no pertenece a nadie y a todos, puede ser de cualquier lugar o de ningún lugar específico. La otra ideología parte de la autenticidad y sitúa el valor de la lengua dentro de una comunidad particular, de la cual el idioma expresa de forma genuina su esencia, sus raíces y su memoria. Este tipo de ideología es común en procesos de legitimación de lenguas minoritarias o también de variedades estigmatizadas.

En resumen, y de acuerdo con los argumentos examinados, la Romania conforma un espacio pluridimensional: geográfico, lingüístico, histórico, político, social y humano. Además y dentro del contexto actual, ese espacio se ve atravesado por discontinuidades y convergencias, por dinámicas centrípetas y centrífugas; y si, por un lado, un reducido grupo de grandes lenguas - pertenecientes al club románico- tratan de consolidar la propia posición global frente al inglés, lengua hipercentral; por otro lado, un mosaico de idiomas, dialectos, variedades, jergas y hablas locales reivindican su existencia en la diversidad. Al mismo tiempo, las lenguas no ocupan una posición estática, sino que asumen posiciones más o menos hegemónicas o subordinadas según los contextos. La suma de estas relaciones servirá para sustentar nuestra propuesta de traducción intrarrománica, como se verá en el quinto epígrafe del artículo; pero antes debemos tratar el papel que ha jugado la traducción en las diferentes comunidades hablantes de latín o de romance a lo largo de su historia.

\section{Las tradiciones traductológicas en el ámbito latino y románico}

Como ya hemos señalado en epígrafes anteriores, el proceso de traducción conlleva una mediación entre culturas y tradiciones diversas. Al mismo tiempo, cada cultura posee una tradición literaria y lingüística propia; también una tradición de traducción. Levý (2011: 75) llama la atención sobre la dicotomía traducción/tradición y afirma:

Unlike creative acts by original artists, reproductive activity is repetitive, so in the case of more frequently translated major works an interpretative tradition becomes established. In translation practice, as in acting, each new translator takes account of previous interpretations, learning from his predecessors' experience and possibly also succumbing to the same pitfalls.

$\mathrm{Al}$ abordar la traducción entre lenguas procedentes del latín, no debemos olvidar que la tradición de la traducción en Occidente tiene origen en la antigua Roma, cuya cultura se convirtió en una cultura de traducción desde época temprana. El propio 
Berman (1995) señala que para nosotros, como Occidentales, la traducción tiene un origen, un lugar y una fecha de nacimiento. La literatura latina emergió como traducción de la literatura griega, que los romanos admiraban; por consiguiente: "Nous traducteurs sommes et resterons Romains, même s'il nous faut lutter contre certains aspects de la romanité en nous: même si, dans une certaine mesure, il nous faut devenir des Grecs et des Juifs" (Berman 1995: 21).

Más tarde, durante la Edad Media, las primeras literaturas en romance surgen en un contexto de traducción de las lenguas clásicas a las vernáculas o vulgares; así la novela nace en el norte de Francia cuyas culturas regionales actúan como culturas de traducción al verter parte de la épica grecorromana y de la mitología céltica y germánica en las lenguas d'oïl, actividad que recibe el nombre de arromanzar. Observamos que la traducción aparece en momentos cruciales como medio de producción literaria a lo largo de los siglos y en diversos dialectos, hablas e idiomas generados por la lengua de Roma. Esa literatura traducida se integra en el polisistema literario de una cultura, de una nación; por esa razón, la existencia de dichas tradiciones es el factor y el facto (el hecho) de la variación en el ámbito lingüístico cultural que aquí tratamos.

En diálogo con esta línea, Berman (2002) se pregunta qué somos, si somos un pueblo de traductores. Resulta difícil determinar a quién incluye en ese somos: ¿se refiere al ámbito académico francés o a la tradición occidental que parte de las traducciones que los romanos hicieron de la lengua y de la cultura griega? Ensayando una respuesta, el autor propone dirigirnos preferentemente hacia lo que, en nuestra cultura, se ha vuelto extranjero pero que constituye, en realidad, nuestra naturaleza más propia, nuestro pasado. Así plantea el problema de la traducción de una cultura latinoamericana oral y popular para una cultura francesa, (latino) europea letrada.

De acuerdo con Hall (2005), las identidades no son fijas sino maleables, dependen del uso de recursos que la historia, el lenguaje y la cultura proporcionan para producir no tanto lo que somos, sino lo que seremos. En otras palabras, al entender la memoria vinculada al presente, y no al tiempo ancestral, es posible explicar qui erimus (quién seremos) a partir de qui eramus (quién éramos). En ese sentido, una propuesta de traducción desde, para y entre lenguas románicas plantea un diálogo entre identidad y alteridad no como discusión entre yo y el otro sino, más bien, como integración de un nosotros en el que las lenguas y culturas de partida y de llegada son partícipes, de múltiples formas, de la Latinidad. Asumir esta posición permitirá, al traductor o al investigador, abordar la materia de su trabajo con mayor grado de coherencia y, al mismo tiempo, entender que las fronteras entre las lenguas románicas no son inmóviles ni definitivas, sino permeables a influencias reciprocas, pues beben todas de una fuente común.

\section{Una propuesta de traducción intrarrománica}

La visión más común actualmente de la traducción entiende las lenguas modernas como compartimentos cerrados, como realidades discretas. De esa forma, percibimos las lenguas románicas (español, francés, italiano, portugués, catalán, gallego, rumano y las demás) como códigos diferentes entre sí y también diferentes respecto al latín, origen y nexo de todas ellas, a pesar de las analogías entre unas y otras 
que, todavía hoy, posibilitan cierto grado de intercomprensión y comunicación exolingüística entre sus hablantes. Según Wright (1976) y Finbow (2011), esa polarización es el resultado de la consolidación de algunas lenguas como idiomas nacionales en el pasaje de la Edad Media a la Edad Moderna, entre los siglos XV y XVI. Estas nuevas entidades políticas demarcaron progresivamente fronteras sobre el fluido continuum lingüístico que había caracterizado al territorio de la Romania durante más de un milenio. De acuerdo con Grutman (2001), las lenguas románicas, principalmente las seis o siete que cuentan una norma estándar más sólida, son vistas como lenguas europeas, adyacentes a otros idiomas del continente de matriz germánica, helénica o eslava con los que comparten, en buena medida, una tradición occidental y europea; diferenciadas así de idiomas más alejados en el plano lingüístico y cultural como el árabe, el mandarín, el japonés o el suajili.

Ahora bien, contrastando con las citadas separaciones entre normas estandarizadas, Berman (2007: 11) entiende que a la traducción le corresponde hacer el camino en sentido contrario para regresar al "corazón materno de la lengua materna como espacio de acogida" y "de polifonía dialectal". Para ese corazón materno de la lengua materna, todas las lenguas son próximas y parientes. Si, de acuerdo con Levý (2011: 84), las especificidades culturales e históricas de la lengua de llegada sustituyen a las especificidades culturales e históricas de la lengua de partida durante el proceso de traducción; corresponde al traductor "buscar (y encontrar) lo no normalizado de la lengua materna para introducir allí la lengua extranjera” (Berman 2007: 122). Así, una propuesta de traducción intrarrománica tratará de hallar lo que une la lengua de partida y la lengua de llegada; es decir, el continuum al cual ambas pertenecen. En ese sentido, es posible establecer una relación entre el concepto de traducción intrarrománica que nosotros proponemos y el concepto de repatriación que Berman (2007: 126) define como el retorno al dominio de la lengua que nos vio nacer y que nos alimentó durante siglos, restando después a nuestro lado. Aplicando dos conceptos más del pensamiento de Berman (2007) a nuestro campo de investigación, una propuesta de traducción intrarrománica debe recuperar aquellos puntos en los que libertad y literalidad se unen para aproximar naturalmente las múltiples variantes neolatinas y el acervo literario de más de dos milenios que este grupo lingüístico atesora.

Como expusimos en el tercer epígrafe, la norma estándar de un idioma, por lo general, no se corresponde totalmente con las variedades vernáculas sino que constituye una proyección codificada basada en el análisis normativo de ciertos sociolectos. Por ello, en el ámbito neolatino, las variedades habladas y las respectivas normas estándar presentan fenómenos a nivel fonético, fonológico, morfosintáctico, léxico y pragmático, ora considerados cultos por una comunidad, ora juzgados vulgares por otra; relegados en una lengua a variedades periféricas y arcaizantes o integrados en las variedades de prestigio y en la norma culta de otra ${ }^{9}$. Por esta razón, si

9 Existen en nuestras sociedades instituciones, como las academias o los sistemas educativos, que ejercen una fuerza centrípeta sobre el idioma, moderando los cambios lingüísticos. Las diferencias entre las lenguas neolatinas estandarizadas se deben en parte a que las fuerzas que actúan en cada lengua y en cada sociedad son en la actualidad y han sido históricamente diferentes. 
la lengua extranjera se sustituye meramente por la norma estándar de la lengua de llegada, perderá sus valores característicos. Esto es especialmente importante en la traducción literaria ya que las obras de los más diversos géneros plasman un espacio plurilingüe, en muchas ocasiones, con objetivos estéticos; el uso de una palabra o de un giro arcaizante en un poema, la aparición de marcas diatópicas o diastráticas para caracterizar un personaje son ejemplos que ilustran lo dicho. Al mismo tiempo, como explica Levý (2011: 98), un determinado dialecto -o registro en la lengua de llegada- puede resultar más próximo o adecuado para acoger la lengua de partida.

En otras palabras, las partes menos estandarizadas de la lengua de llegada abren todo un abanico de posibilidades para acoger la poética de la lengua de partida, devolviéndola, en cierto modo, a la polifonía del continuum románico anterior al advenimiento de las lenguas estandarizadas, un panorama ecolingüístico de límites permeables, una red lingüística, literaria y cultural porosa que tornaba la experiencia de lo extranjero sorprendentemente familiar.

En este punto, debemos explicar qué vías proponemos para retornar al continuum dialectal polifónico. Ciertamente, fue el devenir histórico lo que determinó que algunas variedades llegaran a recibir el status de lenguas mientras que otras no pasaron de dialectos o, todavía más restringido, hablas. Las lenguas como objetos, como construcciones culturales, están envueltas en una red de representaciones sociales y creencias, en un imaginario colectivo. Es interesante para nuestra exposición explicar brevemente los papeles que los estudios poscoloniales atribuyen a la traducción. Para Robinson (1997) la traducción ha servido históricamente como canal de colonización, como pararrayos de las desigualdades culturales y, en última instancia, como canal de descolonización. A su vez, Cronin (1998) entiende la traducción como triangulación entre los vértices del universalismo y de la diferencia; definición que equivale al segundo y al tercero de los papeles de Robinson. Resulta evidente que si la traducción se pone al servicio de una lengua minoritaria permitirá abrir una vía para difundir, desprovincializar, la producción literaria sin amenazar el carácter genuino de ese idioma al tiempo que crea nuevos canales de difusión en las lenguas de llegada.

Por este motivo, es necesario substraer temporalmente las relaciones que estructuran de manera jerárquica la familia neolatina, que atraviesan el espacio pluridimensional de la Romania, para desnudar las hablas románicas y hacer de ellas lengas nusas (lenguas desnudas), adoptando la propuesta del occitanista Sauzet (2008). Explorar, presentar y evaluar elementos que auxilien la traducción entre lenguas románicas abre nuevos canales de comunicación entre esos idiomas y las comunidades que los hablan, produciendo lo que Holmes (1972/1988/2000: 67) denomina "a new disciplinary utopia". Un ideal de traducción que otorga una posición central a los lazos que tan íntimamente las unen y, de cierta forma, articula un movimiento en dos sentidos sobre el eje diacrónico de la lengua de llegada ya que, a través de esta conmoción con la lengua extranjera, la lengua materna accede a partes insospechadas de su ser, partes que muy probablemente no lograría alcanzar solo con su propia literatura, parafraseando a Berman (2007: 131). En este ideal, se despliega una doble temporalidad lingüística que devuelve a la lengua la memoria de su his- 
toria y de sus orígenes y le abre un futuro de posibilidades insospechadas; dejando entrever, por el simple juego de las palabras en el espacio, el largo destino de la lengua, cumpliendo la afirmación de Foucault citada por Berman (2007: 126).

Hasta aquí, presentamos una propuesta de traducción entre lenguas románicas que partiese del continuum lingüístico, literario e histórico que todas ellas comparten. Sin embargo, esa propuesta no puede ignorar que las asimetrías que también existen al interior del grupo puesto que, como apuntaba Levý (2011: 48), ningún idioma es isomórfico a otro. Tales asimetrías y diferencias no son exclusivamente de naturaleza lingüística sino que también se encuentran entre tradiciones literarias, géneros textuales, estructuras métricas, rítmicas y estróficas; todo ello crea una tensión estilística en el proceso de la traducción:

Stylistic tension. Apart from difficulties caused by incommensurability between the two languages and the influence of the linguistic characteristics of the source on the translation, translators are at a disadvantage because the translation is not original in its expression, i.e. because ideas are re-stylised ex post facto, using verbal material by means of which and for which they were not originally created. (Levý 2011: 52)

Consideramos que el impacto de esas tensiones lingüísticas y estilísticas es justamente lo que hace que tenga sentido formular una propuesta de traducción intrarrománica, como herramienta metodológica que logre vincular de manera coherente lo que, de otro modo, se estimaría difuso o inconexo, conformando una red capaz de absorber dichas tensiones. Y, en este horizonte, se perfilan las relaciones entre estos idiomas $-\mathrm{y}$ sus respectivas comunidades de hablantes- que no son sino el grado y la manera en que todos ellos participan de la Latinidad.

En definitiva, los argumentos que aquí presentamos tienen un carácter propositivo y pretenden abrir vías para los investigadores -y traductores- que se propongan trabajar dentro de la esfera que originó la lengua de Roma.

\section{Conclusiones y perspectivas para futuros estudios}

A lo largo de estas páginas hemos tratado de delinear un área interdisciplinar entre una disciplina relativamente reciente, la traductología, y otra que cuenta con casi doscientos años de historia, la romanística (es decir, la filología y la lingüística románica), en la cual se pueden inscribir aquellos estudios teóricos, restringidos a dicho grupo lingüístico. Además, utilizamos investigaciones y conceptos procedentes de diferentes áreas - como los estudios culturales, la geografía, la historia, la lingüística románica, la filología románica y la literatura- para guiar nuestra exposición. Nos parece que ello prueba la naturaleza interdisciplinar de la traductología en un momento en que el ámbito académico y universitario está repensando la segmentación y especialización del conocimiento, así como la necesidad de abrir espacios de diálogo e intercambio entre áreas más o menos próximas para conseguir avanzar en la producción científica. Asimismo conside- 
ramos que la integración de disciplinas y campos del saber no ha de servir para hacer simplemente la suma de dos o más ciencias, sino para alterar el cálculo de saber y de poder redefiniendo los objetivos de nuestras instituciones académicas y educativas.

De acuerdo con los objetivos de nuestra investigación, y adoptando enfoques y conceptos de varios campos del conocimiento, presentamos la diversidad intrínseca a las lenguas románicas y las estrechas relaciones que varios de estos idiomas establecieron con la traducción en diferentes momentos de su desarrollo histórico. Berman (2007) enuncia trece tendencias que se presentan en el proceso de traducción y que, de diversos modos, alejan el texto en la lengua de llegada de la obra original. Sin embargo, una buena comprensión de la letra del original, inscrita en su contexto cultural, lingüístico y literario, por parte del traductor le permitirá evaluar y modular el impacto de dichas tendencias apoyándose en los aspectos compartidos. Dentro de la familia románica, esto es posible gracias al continuum que permanece en la base de las diferentes lenguas estándar, a la proximidad lingüística, al contexto histórico cultural compartido, así como a cierto grado de inteligibilidad mutua. Elementos que amplían las posibilidades y potencialidades de la traducción e intercomprensión literaria y cultural entre sistemas lingüísticos próximos. Cabe destacar también que nos referimos a elementos siempre en plural ya que cada uno de los ítems examinados no actúa independientemente, por el contrario, todos ellos se suman para tejer la red que describimos a lo largo de nuestra exposición.

Es cierto que los investigadores pueden juzgar el legado compartido y las tradiciones análogas como bastantes, insuficientes e incluso excesivas para guiar sus trabajos dependiendo de los paradigmas que defiendan. A nuestro entender - es decir, de acuerdo con los paradigmas que describimos, examinamos y empleamos- esta propuesta de traducción intrarrománica permite organizar las relaciones culturales, lingüísticas y literarias existentes en el orbis latinus, en el espacio pluridimensional de la Romania. Después corresponderá a cada investigador o traductor la tarea de establecer cómo dichas relaciones pueden contribuir en su propio proyecto de traducción. Futuros estudios, artículos, trabajos académicos o tesis, aplicados a este grupo lingüístico en su conjunto o a un par lingüístico específico, servirían para validar o refutar las ideas que aquí expusimos y analizamos.

En todo caso y dentro de esta área específica, tales trabajos deberán contribuir no tanto a desarrollar teorías -según Berman (2007) prescindibles para la traducción y para la traductologia- sino, más bien, a construir una reflexión, un pensamiento a partir de un horizonte lingüístico, crítico, literario, histórico y filosófico. Pues, como apuntaba Bhabha (2010), es en los espacios intersticiales, en las fronteras de la historia y del lenguaje, en los límites de la diversidad y de la identidad humana, donde se pueden crear las condiciones para traducir las diferencias en una especie de solidaridad. En ese contexto, la traducción no se plantea como una mediación entre la lengua propia y la lengua del otro sino como la translación (el desplazamiento) entre las lenguas de nosotros, plurales y próximas. 


\section{Referencias bibliográficas}

Badia y Margarit, A., "Génesis de la Romania y genio de la romanística», en: Gargallo Gil, J.; Reína Bastardas, M. (eds.), Manual de lingüistica románica. Barcelona: Ariel, 2007, 25-44.

BAgno, M., «O Português não procede do latim: uma proposta de classificação das línguas derivadas do galego», Grial Revista Galega de Cultura 191 (2011), 34-39. Disponible en web: http://goo.gl/ZCPzu1

Berman, A., Pour une critique des traductions: John Donne. Paris: Gallimard 1995.

Berman, A., A prova do estrangeiro: cultura e tradução na Alemanha romântica: Herder, Goethe, Schlegel, Novalis, Humboldt, Schleiermacher, Hölderlin. Bauru/São Paulo: EDUSC 2002.

Berman, A., A tradução e a letra ou o albergue do longínquo. Rio de Janeiro: 7 Letras 2007.

BнавHA, H., «Diseminación, tiempo, narrativa y los márgenes de la nación moderna», en: BhabHa, H. (ed.), Nación y narración. Buenos Aires: Siglo XXI, 2010, 385-421.

CAlvo del Olmo, F., «La Romania: ebauche d'un carrefour linguistique», Mutatis Mutandis 5-2 (2012), 391-409.

CAlvo Del Olmo, F., "Tradução, língua e identidade em poetes occitanos e catalães do século XIX: elementos para uma tradução entre línguas românica». Dirigida por Mauri Furlan. Tesis doctoral inédita: Universidad Federal de Santa Catarina, Programa de posgrado en Estudios de la Traducción, Florianópolis, 2014. Disponible en web: http://goo.gl/XVnP4F

Cronin, M., «The Cracked Looking Glass of Servants: Translation and Minority Languages in a Global Age», The Translator 4-2 (1998), 145-62.

FinBow, T., «Políticas da norma», en: Lagares, X; Bagno, M. (eds.), Políticas da norma e conflitos linguísticos. São Paulo: Parábola, 2011, 49-88.

Grutman, R., «Multilingualism and translation», en: BAKER, M. (ed.), Routledge Encyclopedia of Translation Studies. Londres/Nueva York: Routledge, 2001,157-160.

HALl, S., "Quem precisa de identidade?», en: Silva, T. (ed.), Identidade e diferença: a perspectiva dos estudos culturais. Petrópolis: Vozes, 2005, 103-133.

Holmes, J., «The Name and Nature of Translation Studies», en: Holmes, J., Translated! Papers on Literary Translation and Translation Studies. Amsterdam: Rodopi, 1972/1988/2000, 67-79.

LAgares, X., «Minorias linguísticas, políticas normativas e mercados», en: LAGARES, X; Bagno, M. (eds.), Políticas da norma e conflitos linguísticos. São Paulo: Parábola, 2011, 169-192.

Lagares, X., «O galego e os limites imprecisos do espaço lusófono», en: MoITA LOPES, L. (ed.), O português no século XXI: Cenário geopolítico e sociolinguístico. São Paulo: Parábola, 2013, 361-393.

Levy, J., The Art of Translation. Amsterdam/Filadelfia: John Benjamins Publishing Company 2011.

Metzeltin, M., Las lenguas románicas estándar. Historia de su formación y uso. Oviedo: Academia de la Llingua Asturiana 2004.

MiLroy, J., «Ideologias linguísticas e as consequências da padronização» en: LAGARES, X.; Bagno, M. (eds.), Politicas da norma e conflitos linguísticos. São Paulo: Parábola, 2011. p. $50-87$.

PosNeR, R., Las lenguas romances. Madrid: Cátedra 1998.

RENZI, L., Introducción a la filología románica. Madrid Gredos 1982. 
RenZi, L.; Andreose, A., Manuale di Linguistica e Filologia Romanza. Bologna: Il Mulino 2009.

RoBInSON, D., Translation and Empire. Manchester: St Jerome 1997.

SAUZET, P., «Se pòt existir una lenga sens una marina de guèrra», en: MASSIP, À. (ed.), Llengua i identitat. Barcelona: Edicions Universitat de Barcelona, 2008, 109- 130.

Tagliavini, C., Orígenes de las lenguas neolatinas. Madrid: Fondo de Cultura Económica 1993.

Wright, R., «Speaking, Reading and Writing Late Latin and Early Romance», Neophilologus 60 (1976), 178-89. 